\title{
III. Zur Casuistik der Wirkung der Thermen von Neuenahr bei chronischen Blasenleiden.
}

Von

Dr. E. Mämzel,

Badearzt zu Neuenahr.

(Schluss aus No. 25.)

Fall 2. Herr W. aus R. 57 Jahre alt, Rentier, frïher Kaufmann, von gesunden Eltern stammend. - Ausser Scharlach und Masern, die er als Kind, beide mit leichtem Verlauf durchmachte, - - ar er bis zu seiner jetzigen Erkrankung meist gesund. Zur Zeit klagte Patient über grosse Mattigkeit, Abgeschlagenheit, mangelhaften Schlaf, Appetitlasigkeit, Stuhlverstopfung, grosse Empfindlichkeit gegen Witterungseinflüsse, häufigen sehr lässigen Drang zum Uriniren, Abgang scharf riechenden, dickschleimigen, mitunter blutige Streifen enthaltenden Harnes. Das Leiden begann vor ca. 10 Jahren in unmittelbarem Anschluss an eine intensive Durchnässung und Erkältung unter den Zeichen eines acuteu Blasenkatarrhes. Dasselbe dauerte bei medicamentöser Behandlung mehrere Wochen und verschwand vollständig. Mehrere Monate darnach folgte eine abermalige stärkere Erkältung, an die sich auch sofort ein Reoidiv des vorigen Leidens anschloss, der Verlauf war diesmal minder heftig, aber von längerer Dauer als im ersten Fall." Auch hinterblieb jetzt ein häufiger Drang zum Uriniren und jede selbst die geringste Abkühlung oder das Trinken jungen Weines und Bieres, riefen die alten Beschwerden in bedeutendem Grade hervor. Nach und nach wurden unter Auftreten neuer stärkerer Exacerbationen die Beschwerden immer grösser : der Harn nahm eine trübe Farbe an, wurde übelriechend, dickschleimig etc. kurz das Lciden wuchs mit den Jahren zu seiner jetzigen Höhe heran. Medicamentöse Behandlung, Bäder, strengste Diät, Blasenausspülungen mit warmem Wasser und arzneilichen Lösungen schafften nur vorïbergehenden Nutzen. Seit ca. 6 Jahren besucht der Kranke alljährlich im Sommer Neuenahr, ging auch uach 4 bis 6 wöchentlicher Kur jedesmal wesentlich gebessert in seine Heimath. Aber meist im Spätherbst kamen die alten heftigen Symptome mit ihrer Qual, als unliebsame Gäste ins Haus. Zu seinen damaligen Trinkkuren benutzte Herr W. die leichteren Quelten; Augusta und Victoria, zuletzt den Sprudel, welchen er in dem letzten Sommer gleich von Anfang an trank. Von Zeit zu Zeit nahm er Sitzbäder. Seine Diät war zweckentsprechend reizlos und kräftig. Als Getränk bekam ihm ein Glas guten alten Rothweins von der Ahr am besten. Zur Erfrischung trank er kohlensaure Wässer.

Bei jeder Verschlimmerung des Blasenkatarrhes ging der Kräftezustand des Kranken beträchtlich zurück, Verdauungsstörungen, besonders Obstructionen, Dyspepsie, eine äusserst melancholische Stimmung waren constante Begleiter derselben. Dies ewige, lästige und ompfindliche Harndrängen, durch welches er ununterbrochen an sein trostloses Leiden erinnert wurde und welches ihm den ruhigen Schlaf ranbte, verscheuchte ihn auch aus der Gesellschaft und von jeder Gelegenheit zur Zerstreuung.

Bei grosser Hitze traten ebenfalls die Symptome heftiger hervor, walırscheinlich in Folge der durch die stärkere Transpiration der Haut bedingten Concentration des Urines.

Der Kranke ist von kräftigem Körperbau, äber mittlerer Statur, mässiger Feltentwickelung.

Das bleiche, fast kachectische Aussehen seiner Hautdecken, der etwas düstere Gesichtsausdruck, die belegte Zunge, die schlaffe Musculatur und welke Haut, bei im Ganzen noch leidlicher Ernährung, bilden die zunächst sichtbaren Symptome einer vorhandenen tärrkeren Störung. Im Bereiche der nervösen Centralorgane, der Nerven, des Herzens, der Gefässe, Lunge, Leber, Milz lassen sich keine Symptome auffallender Abnormitäten nachweisen. Krankhafte Zeichen sind: grössere Empfindlichkeit bei Druck auf die Blasengegend und schmerzhaftes Gefühl bei etwas kräftigerem Druck auf die Magengegend, ohne dass dort oine abnorme Dämpfung vorhanden wäre; nur fühlt sich die Stelle taber der Symphyse etwas resistenter an. Die äusseren Genitalien sind normal. Eine combinirte Untersuchung zwischen Reetum und Hypogastrium ergiebt weder abnorme Geschwulst der Blase noch der Prostata. Der möglichen Annahme einer Strictur der Urethra widerspricht der leicht einfihrbare Katheter 
durch den sich auch Steinbildungen in der Blase ausschliessen lassen. Legt man den Katheter nach dem Uriniren ein, so gehen noch ein bis zwei Esslöffel dicklichen Urins ab, der nicht freiwillig entleert werden konnte. Der Urin geht freiwillig, in gutem Strahle fort, nur ruckweise kommen, diesen plötzlich sistirend, Unterbrechungen vor, ähnlich wie bei Steinkranken; und erst nach kräftiger Wirkung der Bauchpresse, nach Secunden langer Pause kommen dickschleimige, froschleichähnliche fadenziehende, lange Pfröpfe in ziemlicher Quantität, denen dann wieder Urin im Strahl folgt. Der Urin selbst zeigt sofort nach dem Uriniren stark ammoniakalischen üblen Geruch und stark alkalische Reaction. Seine Farbe ist dunkel weingelb, er ist undurchsichtig und kurz nach dem Stehen, setzt sich, die Hälfte der Urinmenge bildend, eine dicke halbtrübe schleimige, sehr zähe Masse mit eingestreuten weisslichen Partikeln von Stecknadelkopfgrösse in dem betreffenden Gefässe zu Boden. Dann und wann finden sich darin einzelne erbsengrosse, schleimige Fetzen, welche blutig gefärbt sind.

Die chemische Untersuchung ergiebt ausser starkem Ammoniakgehalt, ziemlich viel Eiweiss. Unter dem Mikroskop sieht man die grossen Pflasterepithelien der Blase, Eiter und Schleimkörperchen, Mikrocoecen, Krystalle von Phosphorsaurer Ammoniakmagnesia, harnsaures Ammoniak. Cylinder aus den Nieren sowie die charakteristische Epithelien derselben waren ebensowenig, wie andere Formelemente, welche auf einen malignen Process im Urogenitalapparat schliessen lassen konnten, aufzufinden.

Die angegebene Beschaffenlıeit des ammoniakalischen Harnes rührte offenbar theils von vermehuter Schleimabsonderung, theils und der Hauptsache nach, von den gelösten Eiterzellen her; welch letzteren er, da andere Quallen der Albuminurie auszuschliessen waren, seinen Eiweissgehalt verdankte.

Beim Beginn der Kur liess ich neben täglichem möglichst langem Aufenthalt in freier Luft den Kranken Sprudel trinken, hegann mit $60 \mathrm{Grm}$. pro die bis $1000 \mathrm{Grm}$. steigend für zwei Tageszeiten je $500 \mathrm{Grm}$. Später verordnete ich noch eine dritte Portion eine Stunde vor dem Mittagstisch, so dass allmälig der Kranke täglich $2000 \mathrm{Grm}$. Brunnen trank. Die Wirkung war eine präcise und sehr gute; sofort zeigte sich wie bei allen Brunnentrinkenden Kranken, eine starke Anregung der Diurese, der Urin wurde klarer, enthielt weniger Schleim und Eiter und verlor nach und nach seine alkalische Reaction. Nach drei Wochen reagirte derselbe schwach sauer und unterschied sich nur noch durch etwas grësseren Schleimgehalt von gesundem Harn. Nur Nachts, und dies war bei allen früheren Kuren geblieben, fand sich stets die alte Plage ein und frühmorgens wurde wieder dicker ammoniakalischer Harn entleert. Da ich eine energisch fortgesetzte Diurese, zur fleissigen Ausspülung der Blas auf dem nattirlichen Wege, für das erste Erforderniss hielt, liess ioh den Kranken den Brunnen mit ins Bett nehmen, vor Schlafengehen und beim ersten Erwachen in der Naclit je eine Quantität von 250 his $300 \mathrm{Grm}$. trinken. Der Erfolg war ausgezeichnet; innerhalb acht Tagen war der Harn bis auf etwas vermehrten Schleimabsatz normal zu nennen; die sämmtlichen Beschwerden des Kranken verschwunden. Die übrige Behandlung erstreckte sich zur Abhärtung des Patienten auf warme, allmälig kühlere Sitzbäder bis $\mathbf{2 4}^{\circ} \mathrm{R}$. fallend, darauf folgende valte Waschungen des Unterleibes und Dammes, denen ich als Hautreiz eine flächtig gemachte spirituöse Abreihung folgen liess. Zugleich entlastete ich mit grosser Vorsicht den Kranken allmälig seiner überflüssigen Kleiduugsstücke. Die Diät war nahrhaft, möglichsı reizlos, der Genuss von einigen Gläsern alten, rothen Ahrweines erlaubt. -

Die Kräfte des Kranken hoben sich ausserordentlich rasch, Appetit, Verdauung regelten sich, Schlaf war wieder normal, so dass sich der verdriessliche, grämliche Patient, innerhalb sechs Wochen in einen heitern, liebenswürdigen alten Herrn verwandelt hatte. - In seiner Heimath rieth ich dem Kranken den Brunnen noch einige Wochen zu trinken, dann Sprudelsalz in warmem Wasser gelöst zu substituiren und innerhalb sechs Wochen zur gewöhnlichen Lebensweise zurückzukèren, was auch geschehen ist.

Ob die Kur von Dauer? Ich selbst firchtete, dass Patient, wie er früher alljährlich eine Verschlimmerung seines halbgebesserten Zustandes im Herbst erfahren hatte, auch diesmal einen ungünstigen Einfluss der kalten, nassen Jahreszeit. - Aber meine Befürchtungen waren grundlos, denn im. Beginn April bekam ich von meinem früheren Kranken die erfreuliche Nachricht, dass er von seinem Leiden noch gänzlich befreit sei und sich vortrefflich befinde.

Den günstigen Einfluss unserer Quellen, besonders des Sprudels, erkläre ich mir aus Folgendem: Durch die kohlensauren Alkalien wird, und dies ist hier fast durchgängig der Fall, eine äusserst rege Diurese bewirkt. Der Sprudel enthält, laut Analyse, der Hauptsache nach, sehr viel Kohlensäure und zwar trotz seiner Temperatur von $32^{\circ} \mathrm{R}$. s e hr fest gebunden (diese entweicht selbst nach stundenlangem Stehen an der Luft kaum merklich) in einer Lösung von doppeltkohlensaurem $\mathrm{Na}$ tron, Magnesia und Kalk. - Die Magentemperatur, noch geringer als die
Quellentemperatur, ist für sich allem nicht im Stande nennenswerthe Mengen von Kohlensäure aus den genossenen Brunnen auszutreiben, denk trołz des kräftig prickelnden Kohlensäuregeschmackes des Sprudels bemerkt man, wenn nicht excessive Säurebildung im Magen stattfindet, kein, oder kein nennenswerthes Aulstossen nach dem Trinken. - Der Brunnen wird meist bei leerem Magen genommen und so wird ein ziemliche Menge Kohlensäure mit der alkalischen Lösung resorbirt und unter starker Steigerung der Diurese der Blase als solche im Harn wieder zugeführt. - Die rasch wechselnde Füllung und Entleerung der Blase verhindert oder erschwert das Zersetzen des Ürins; die Kohlensäure bindet das vorher durch die Zersetzung gebildete freie Ammoniak zo einfach- und doppeltkohlensaurem Salz. In Folge davon geringere Reizung der Blasenschleimhaut, Nachlassen der Absonderung von Schleim, Eiter etc. - Ueberschüssige Kohlensäure wirkt dabei zugleich sedativ und antiseptisch und setzt die Hyperästhesie der Blase etwas herab, welche Wirkung bei nicht ammoniakalischem Harn noch prägnanter hervortritt. - So summiren sich nach und nach die kleinen Wirkungen zu der grossen günstigen, in die Erscheinung tretenden, der Heilung des Leidens. - Den besten Beweis, dass die fleissigen und sich ohne grosse Unterbrechungen folgenden Ausspülungen der Blase von den Nieren aus, sehr wichtig sind, liefert der zweite Fall, in dem der Kranke genau dieselbe Kur, jedoch ohne Nachts Brunnen zu trinken, 6 Jahre nur mit palliativem Erfolg gebraucht hatte. - Genau erst von da an, wo der Patient auch Nachts Brunnen trank, wodurch dem Harn auch während der Nacht nicht die nöthige Zeit zur Zersetzung gelassen und damit zugleich eine raschere Entfernung der Gährungselemente bewirkt wurde, reichte eine nur einmalige sechswöchentliche Kur hin, das Leiden zum Verschwinden zu bringen. Im ersten Fall spielt neben der vermehrten diuretischen Wirkung die sedative Wirkung der Kohlensäure auf die Hyperästhesie der Blase wohl die Hauptrolle. Dass in beiden Fällen das gute Resultat, durch den ausserordentlich günstigen Einfluss der Quelle auf die bestehenden Störungen im Verdauungstractus und die besonders bei Fall I vorhandenen Erscheinungen von Reizung der Darmschleimhaut, sowie auf die durch die Obstruction hegünstigten Hämorrhoidalblutungen mit consecutiver Anregung der Blasenhyperästhesie, wesentlich mit bedingt ist, glaube ich ebenfalls annehmen zu dirfen. Dass auch den günstigen klimatischen, von grossen Temperaturschwankungen freien Verhältnissen des schönen Ahrthales ein gewisser Einfluss auf die Heilung der Kranken nicht abzusprechen ist, lässt sich gewiss nicht läugnen.

Analyse der Ilauptquelle Neuertahrs, des grossen Sprudels. Berechnet auf 10,000 Gewichtstheile.

Doppeltkohlensaures Natron . . 10,5000

Schwefelsaures Natron . . . . $\mathbf{0 , 9 0 7 4}$

Chlornatrium . . . . . . . 1,1250

Doppeltkohlensaure Magnesia . . . 4,3795

Doppeltkohlensaurer Kalk . . . $\quad \mathbf{3 , 0 2 4 0}$

Eisenoxyd und Thonerde. . . . 0,1900

Kieselsäure . . . . . . . . $\quad 0,2430$

Kali . . . . . . . . . . . $0,0,2813$

Lithion . . . . . . . . 0,0018

Freie Kohlensäure . . . . . . . $\mathbf{9 , 8 2 7 6}$ Bäder.

Die tägliche Wassermenge reicht aus für bequem 2000 reichliche 